\title{
Postpartum depression during COVID-19
}

\author{
Maria E. Almasidou ${ }^{1,2}$
}

\section{Dear Editor,}

During the COVID-19 pandemic crisis midwives need to be more aware about postpartum depression. Many women who had already planned their childbirth and their life, face now extreme fear and stress. The fear and other health problems ${ }^{1}$ that mothers and infants develop usually appear in the first weeks of labor, including postpartum hemorrhage, fever, infection, abdominal and back pain, and also urinary tract complications that can lead to postpartum depression. Midwives have to be concerned, if postpartum depression was a common problem in one in nine of the women before the pandemic, now it can affect many more women. Women generally want to discuss ${ }^{2}$ their childbirth experience, preferably with the midwife who was present at birth.

In order to comply with social distancing ${ }^{3}$, midwives have to accomplish a psychometric examination via virtual visits with open camera. The midwife at the beginning and during the visit-teleconference should ask the woman questions ${ }^{4}$ related to her current psychological condition. Some of them are:

1. During the last month, did you feel psychologically depressed?

2. During the last month, have you had any interest in doing something?

3. In the last two weeks, how often have you felt nervous or anxious?

If some of the questions are affirmative, she is at risk of developing a psychological instability 4 .

Psychometric examination should be continued using a special EPDS questionnaire ${ }^{5}$. The questionnaire can be completed by the midwife by asking the questions or sending it to the woman to fill in at the time of the conference call, to avoid any interference from other family members. If the results of the answers are worrying, then the woman should be referred to a healthcare professional ${ }^{4,6}$. The midwife must recognize the seriousness of the situation in case of avoidance to respond by the woman or negligence to complete the questionnaire.

Women need to be encouraged to take care of themselves. This includes gentle exercise, time to rest, seeking help in caring for the baby, talking to someone about their feelings, and making sure they can have access to a virtual-midwife ${ }^{4,6}$ at any moment.

In virtual home visits it is not necessary to make many visits, as this will have negative effects such as developing postpartum depression1, but the midwife should provide more psycho-education via the teleconference?

Teleconferencing should be based on empathy (i.e. the fight against negative emotions and loneliness) that helps mothers in their daily lives. In addition, it should be individualized and adapted ${ }^{8,9}$ to each situation and woman.

\section{REFERENGES}

1. Yonemoto N, Dowswell T, Nagai S, Mori R. Home visits in the early period after the birth of a baby. Cochrane. https://www.cochrane.org/CD009326/PREG_home-visitsearly-period-after-birth-baby. Published August 2, 2017. Accessed March 10, 2020.

2. Dahlberg $U$, Hauga G, Aune I. Women's experiences of home visits by midwives in the early postnatal period. Midwifery. 2016;39:57-62. doi:10.1016/j.midw.2016.05.003

3. Word Health Organization. WHO Coronavirus disease (COVID-19) advice for the public. https://www.who.int/emergencies/diseases/novel-coronavirus-2019/advice-forpublic. Updated April 29, 2020. Accessed May 10, 2020.

4. National Institute for Health and Care Excellence. Antenatal and postnatal mental health: clinical management and service guidance. https://www.nice.org.uk/

\section{AFFILIATION \\ 1 Midwifery Department, University of West Attica, Athens, Greece, \\ 2 Hippokration General Hospital, Thessaloniki, Greece}

\section{CORRESPONDENCE TO}

Maria E. Almasidou. Hippokration General Hospital, Thessaloniki, Greece. E-mail: malmasidou@ gmail.com ORCID ID: https:// orcid.org/0000-0002-53396702

\section{KEYWORDS}

midwives, COVID-19, virtual visits, teleconferencing, postpartum depression, EPDS

$\checkmark$

Received: 10 May 2020 Accepted: 13 May 2020 
guidance/cg192/resources/antenatal-and-postnatal-mental-health-clinical-management-and-service-guidancepdf-35109869806789. Published December 17, 2014. Updated February 2020. Accessed May 10, 2020.

5. Vivilaki VG, Dafermos V, Kogevinas M, Bitsios P, Lionis C. The Edinburgh Postnatal Depression Scale: translation and validation for a Greek sample. BMC Public Health. 2009;329(9). doi:10.1186/1471-2458-9-329

6. National Institute for Health and Care Excellence. Postnatal care up to 8 weeks after birth. In: NICE Clinical Guidelines, No. 37. London, United Kingdom: National Institute for Health and Care Excellence; 2015.

7. Shorey S, Chan SW, Chong YS, He HG. Perceptions of primiparas on a postnatal psychoeducation programme: the process evaluation. Midwifery. 2015;31(1):155-163. doi:10.1016/j.midw.2014.08.001

8. Rollans M, Schmied V, Kemp L, Meade T. Digging over that old ground: an Australian perspective of women's experience of psychosocial assessment and depression screening in pregnancy and following birth. BMC Women's Health. 2013;13(1):18. doi:10.1186/1472-6874-13-18

9. Slomian J, Emonts P, Vigneron P, Acconcia A, Reginster J, Oumourgh M, Bruyère O. Meeting the Needs of Mothers During the Postpartum Period: Using Co-Creation Workshops to Find Technological Solutions. JMIR Res Protoc. 2017;6(5):e76. doi:10.2196/resprot.6831

\section{CONFLICTS OF INTEREST}

The author has completed and submitted the ICMJE Form for Disclosure of Potential Conflicts of Interest and none was reported.

\section{FUNDING}

There was no source of funding for this research.

\section{PROVENANGE AND PEER REVIEW}

Not commissioned; internally peer reviewed. 